\title{
Ante el teatro, en el museo, desde el archivo: modos escénicos ( $y$ autorales) del arte contemporáneo
}

María Fernanda Pinta ${ }^{1}$

Irina Garbatzky²

\section{Introducción ${ }^{3}$}

¿Qué temporalidad piensa el teatro? ¿Qué temporalidad piensa el archivo? ¿Cómo entrarían en relación con el museo? ¿Qué efectos arrojan estas proyecciones sobre la práctica curatorial? Al momento de imaginar los nexos entre estos elementos en un relato posible para la muestra Mínimo teatral. Modos escénicos del arte contemporáneo, ${ }^{4}$ partimos de la idea de que estas nociones: teatro, archivo, museo, entran en un contacto que no sólo se orienta hacia una cuestión de contaminación o interdisciplina, sino que su puesta en diálogo permite repensar cada uno de los términos, cuando se relacionan entre sí. Sabemos que el tiempo del teatro, como el de la performance, se acerca notablemente al de un tiempo perdido, en el sentido de que toda reconstrucción de su objeto implica una proliferación de discursos y dispositivos que lo narran o lo registran, pero conociendo desde el inicio que su temporalidad es la del diferimiento: un presente efímero que se repite en cada puesta o se reconstruye mediante una narrativa singular. Sabemos, también, que

\footnotetext{
${ }^{1}$ Doctora en historia y teoría de las artes y profesora de la Universidad de Buenos Aires, Buenos Aires, Argentina. (Dorcid.org/0000-0002-3872-9484. E-mail: pintafernanda@gmail.com

2 Doctora en humanidades y artes (letras) y profesora en la Universidad Nacional de Rosario, Santa Fe, Argentina. (Dorcid.org/0000-0002-1349-0585. Email: irinitag@gmail.com

${ }^{3}$ Una versión preliminar y no publicada de este trabajo fue presentado en el IX Congreso Internacional de Teoría e Historia de las Artes XVII Jornadas del CAIA. "Arte, historia, tiempo. Dispositivos, categorías y usos del tiempo en la historia del arte y la cultura visual", Buenos Aires, del 27 al 30 de septiembre de 2017.

${ }^{4}$ La exhibición tuvo lugar en el Museo de Arte Contemporáneo de Rosario (Macro) desde junio hasta agosto de 2017. Nosotras, María Fernanda Pinta e Irina Garbatzky, fuimos convocadas en calidad de investigadoras invitadas para sumarnos a una curaduría en equipo, integrada además por Eugenia Calvo y Leandro Comba, quienes formaban parte del staff estable del Museo. Cf. Garbatzky (2017) y Pinta (2017).
} 
el tiempo del archivo sería todo lo contrario, el modo de una institucionalización, domiciliación y disposición pública de un acervo documental que se presenta como bien común. El archivo, como marca Jacques Derrida (1997), convoca un espacio arcóntico, patrimonial. La relación entre ambos términos parece, de este modo, complementaria; mientras que el teatro se acerca a la vivencia, a lo que habrá de narrarse de manera experiencial, el archivo recoge las piezas y reconstruye lo que ha sido perdido por el paso del tiempo. Ahora bien, gracias a una valiosísima serie de pensamientos sobre el archivo, - que van desde el propio Derrida, hacia Foucault (1996), Agamben (2002), Farge (1991) -, entendemos que el archivo se encuentra marcado por la incompletud y la performatividad del discurso, - narrar un acontecimiento, propone Derrida, invoca un nuevo acontecimiento -, y que difícilmente la reconstrucción pueda evadir los caminos del arte, la puesta en juego de la palabra y de la imagen, para poder transmitir lo que dio lugar a un acto.

Una de las primeras premisas que tuvimos al momento de comenzar con Mínimo teatral fue que el teatro no ocupara en la muestra el lugar de una representación, un motivo ilustrado o tematizado por obras visuales. El teatro tampoco debía ser el eje temático de un archivo visual que reconstruyera experiencias performáticas (sea en el campo del arte contemporáneo, del teatro o de ambos). De esta manera, la noción de teatro y su forma de exhibición/presentación tenían que ser reinventados hacia dentro de las propias categorías que planteaban los objetos de una exhibición que no se alejaría de la aspiración de un diálogo entre artes visuales y escénicas, aún cuando los intercambios no se produjeran en términos de referencia y/o comentarios de uno con respecto al otro; y que al mismo tiempo no pretendería la formulación de una historia del arte (historia de los campos visual y teatral, historia de sus conversaciones, historia de sus desencuentros), aunque haga una pregunta por la temporalidad y el archivo. En este punto, la propuesta curatorial se planteó desde el inicio como un espacio interpretativo y de producción, alejada de cualquier exigencia historicista o exhaustiva de un tema (como podría haber sido una historia de la relación entre teatro y artes visuales de los últimos cincuenta años). 
El juego con la noción de "mínimo", haciéndonos eco de un concepto trabajado por Vivi Tellas para su teatro, ${ }^{5}$ nos permitió pensar un trabajo de selección, corte y montaje de una serie de artistas, obras y episodios históricos que resultaran significativos para las definiciones y relaciones que la exhibición quería explorar - aun cuando algunas obras no estuvieran inicial y explícitamente vinculadas al teatro. ${ }^{6}$ Se trata, claramente de un lugar ya clásico del curador como autor o artista (o incluso, al decir de Boris Groys, como iconoclasta), no obstante y de manera impensada, ese trabajo de intervención afectó nuestra manera de pensar la relación arte, teatro y archivo, después de realizada la muestra. Sobre esto comentaremos más adelante.

\section{La exhibición y su corpus}

Para el presente trabajo tomamos en consideración una parte de las obras exhibidas, aquella que, creemos, resultará más significativa para los temas y problemas antes comentados.

En primer lugar, la exhibición de distintos registros de audio y video. Sabemos que el registro busca aproximarse a un hecho pasado, en este caso, recuperar una experiencia artística. Y aquí los límites epistemológicos de la empresa (sintetizando: el registro no

\footnotetext{
${ }^{5}$ Vivi Tellas explica: "El trabajo gira alrededor de una idea: buscar la teatralidad fuera del teatro. [...] se ha trabajado con personas comunes y con los mundos reales a los que pertenecen bajo la premisa de que cada persona tiene y es en sí misma un archivo [...]. El contacto y el interés personal por estos mundos es la primera condición para que puedan convertirse en archivos teatrales. La segunda es que tengan algún coeficiente de teatralidad. El interés es ese umbral en el que la realidad misma parece ponerse a hacer teatro: el Umbral Mínimo de Ficción (UMF)". Disponible en: < http://www.archivotellas.com.ar/>.

${ }^{6}$ Nos referimos a la obra de Leticia Obeid (Fantasma, 2015) y Joaquín Aras (Emotion capture, 2016), entre otras, inicialmente más vinculadas al cine y al diseño. Su incorporación en la exhibición seguía las siguientes premisas: "Tradicionalmente se concibe al gesto y a la palabra como expresiones de una interioridad que los precede (emoción o pensamiento). ¿Qué sucede cuando no hay correspondencia entre la palabra, el gesto, su contexto o su traducción? En esa falta de continuidad pueden verse las convenciones que rigen a la palabra y al gesto. También pueden verse los intentos (siempre discontinuos) de la traducción. El teatro y el cine han tenido un lugar privilegiado en este tráfico estilístico de modos de hablar, gesticular y transmitir ideas y sentimientos. Ambos han nutrido nuestro repertorio corporal y lingüístico e inversamente se han alimentado de los sucesivos cambios de época. El mundo digital crea nuevos entornos de diseño, herramientas disponibles para la reproducción de más gestos y más palabras, más ideas y sentimientos. La discontinuidad y la repetición devuelven, sin embargo, un gesto paródico de las correspondencias virtuosas. Las ficciones terminan haciendo síntoma" (Texto de sala).
} 
es ni el hecho ni la experiencia, es lo que la labor investigativa hace con él), funcionaron como puntos de partida; más allá del espectáculo teatral (irremediablemente perdido), los registros se ocuparon de producir una experiencia distinta, lo otro del espectáculo: sus ensayos y también sus efectos en el espectador, el contacto entre la sala y la escena teatral.

El primer conjunto de registros se trató de los ensayos que Vivi Tellas hiciera para el ciclo Biodrama. En su doble rol de directora de cuatro Archivos ${ }^{7}$ y de curadora del ciclo que se desarrolló entre 20022009 en el Teatro Sarmiento, Tellas se pregunta por la vida de las personas a la vez que las piensa como archivos vivos. El resultado, en tanto espectáculo (un teatro documental que combina la mirada y el guión escénico de la artista con la fragilidad y candidez de los actores no profesionales que suben a escena) no se puede ver en Mínimo Teatral. En cambio, se asiste a sus ensayos, en el momento justo en que Tellas hace comentarios y marcaciones y los actores repiten, fallan y vuelven a fallar mejor. Repeticiones y errores también como zonas de hallazgos y aprendizajes.

Para el segundo grupo de registros se seleccionó material de audio de los espectáculos de la Sala del Instituto Di Tella de la década del sesenta (Imagen 1). La sección escamotea deliberadamente la imagen (objeto/registro predilecto del archivo teatral), y presenta fragmentos de una escena mitológica de experimentación teatral argentina de aquella década. La voz de Roberto Villanueva (antiguo director del Centro de Experimentación Audiovisual del Di Tella), convertido en una especie de viajero del tiempo, asume la tarea de explicar el azaroso derrotero del material de audio que llega al visitante, de hacer la historia del Di Tella y de presentar fragmentos de los espectáculos. Y así, como maestro de ceremonias, su voz lejana y reproducida digitalmente activa el mito. El registro vuelve presente finalmente otros fantasmas, los espectadores de aquellos espectáculos, ahora irrecuperables, que con sus risas cómplices, cuando no nerviosas, se vuelven también actores del evento teatral registrado. De este modo, los registros resultan otra cosa respecto de la obra de arte, es un

${ }^{7}$ Los Archivos realizados en el marco del ciclo Biodrama, en 2006, fueron: Disc Jockey, Mujeres guía, Tres filósofos con bigotes y Escuela de conducción. Los registros de video que pudieron verse en la exhibición fueron realizados por Leticia Obeid. 
registro de los procesos de creación o bien de la obra y su recepción, en el momento precario y evanescente de su contacto.

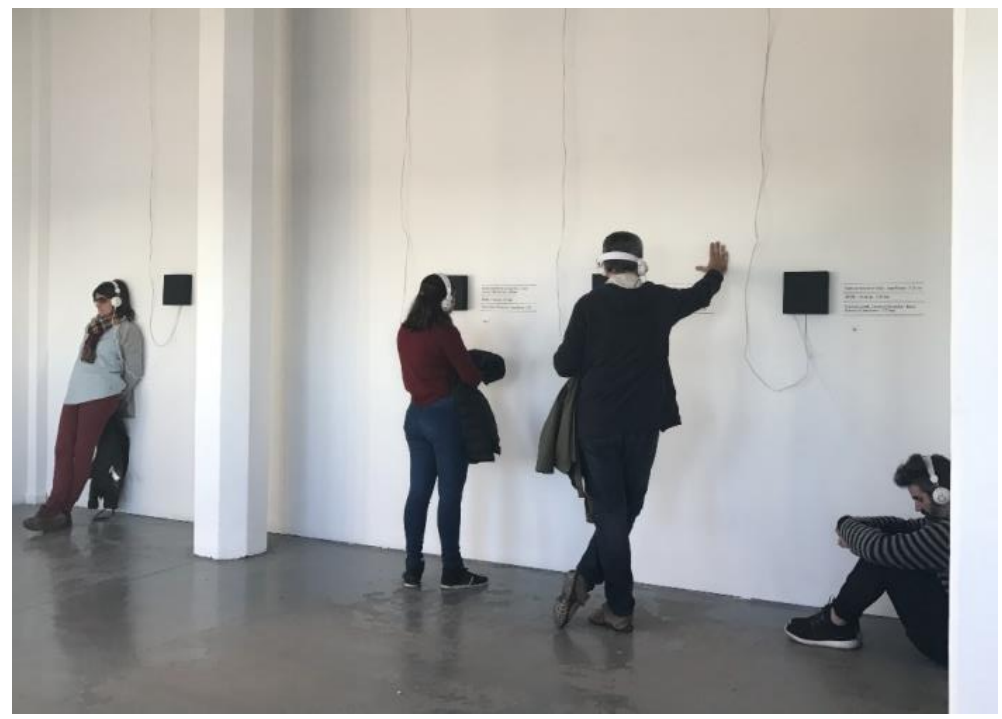

Imagen 1 - Archivo sonoro Di Tella 1

Foto: Federico Baeza

El corpus de la exhibición también contó con la obra de la artista Graciela Carnevale (Imagen 2) en un espacio que se abocó a vislumbrar qué relaciones se tejían entre el teatro (un modo de hacer, una forma de pensar, una manera de activar acciones y contextos) y el archivo personal del artista contemporáneo. Sabemos, desde la historia del arte, el lugar central que ha tenido el teatro y sus legados en el giro performático y conceptual durante el siglo XX. Intuíamos, en este sentido, que la obra de Carnevale nos permitiría pensar en varias cuestiones vinculadas con la intervención y el activismo, y sus concomitantes dimensiones a la vez teatrales e instalativas. Pero "a primera vista", significa antes de encontrarnos efectivamente con Carnevale, quien planteó una serie de puntos de partida que abrieron significativamente no sólo las relaciones con el teatro, sino sobre todo los modos de comprensión del archivo en cuestión. 


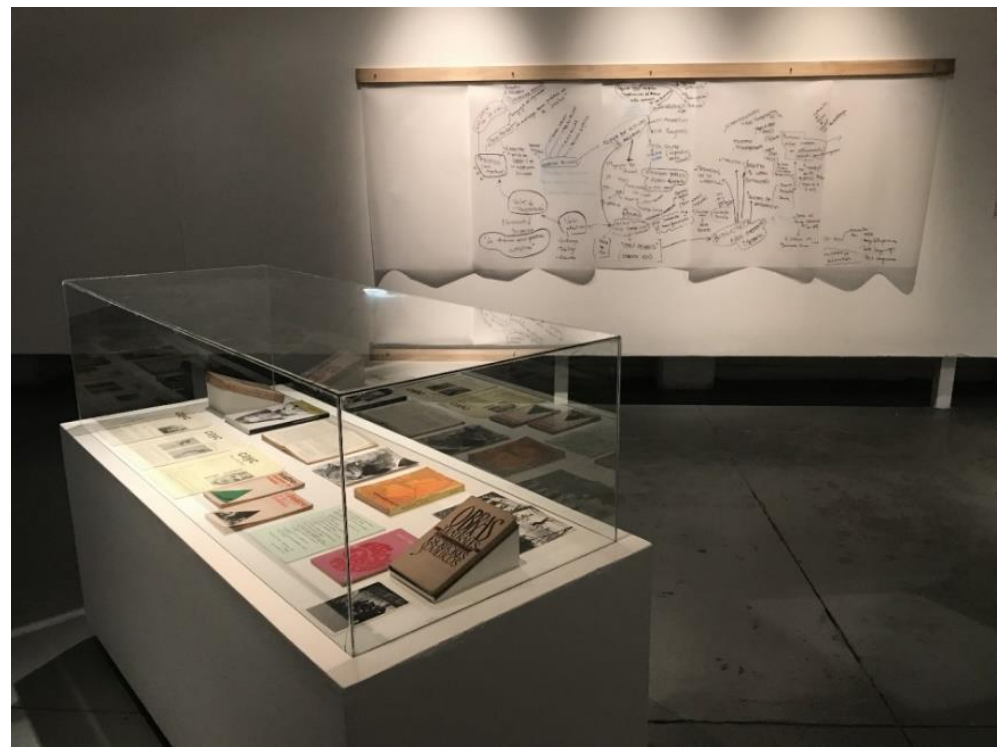

Imagen 2 - Archivo Graciela Carnevale Foto: Federico Baeza

Un primer punto de apertura fue el hecho de encontrar al teatro como un objeto de lectura, uno de los varios (aunque no ilimitados) temas de investigación que actuaron como formación autodidacta del grupo de artistas de vanguardia rosarino. ${ }^{8}$ "Sí, en los años del grupo, leíamos sobre teatro para pensar formas de la acción, de la intervención artística", nos dijo al pasar. Y efectivamente encontramos en la biblioteca llamada "años 60/70" un grupo de volúmenes que tenían relación con el teatro en general y con el teatro de vanguardia de manera más particular: obras de Bertolt Brecht y de Alfred Jarry, el teatro dadaísta, historias y teorías del teatro como intervención social.

Súbitamente el teatro se nos presentó como un elemento doble, no sólo en lo referido al "mínimo teatral", sino como el índice de una serie de discusiones en torno a la acción, una zona que dialogaba con

\footnotetext{
${ }^{8}$ Actualmente el trabajo de Carnevale se vuelca fuertemente a una actividad archivística. La suya es una de las colecciones más completas y casi la única de documentación gráfica de la conocida acción Tucumán arde (1968) en particular y de la intensa actividad artística del grupo de vanguardia rosarino y del argentino especialmente (aunque no únicamente) en los años 60.
} 
otras colindantes, como la "pedagogía del oprimido", el trabajo social o la idea de "obra abierta", de Umberto Eco. Ello se completó, además, cuando Graciela nos mostró las copias del "guión" del Asalto a la conferencia de Romero Brest (escritas muy prolijamente como un verdadero guión performático), y cuando compartió su colección de los programas teatrales del Instituto Di Tella y los cursos del CAYC que guardaba del año 1966, año en que había viajado a Buenos Aires para continuar con sus aprendizajes y vincularse "con el arte de vanguardia en general", según sus palabras.

El archivo, en este sentido, sería menos una reconstrucción exhaustiva del teatro porteño de la época que un recorrido personal, una lógica fragmentaria atravesada por el hallazgo, la curiosidad, la mirada singular. Su puesta en conjunto daba cuenta del trayecto formativo de la joven artista $\mathrm{y}$, en lo referido a la teatralidad, permitía vislumbrar algunas "iluminaciones" o "pensamientos" que habilitaban el teatro como vía para la invención pública y la formulación de nuevos modos de hacer arte y de hacer del arte una praxis vital. La idea de una serie "teatral" dentro del Archivo Carnevale, permitía también pensar cómo abrir y transmitir el archivo, cómo compartirlo y poder entenderlo no como una forma cerrada sino como una instancia afectiva, en constante crecimiento y transformación, un proceso que convocaba una temporalidad ya no vinculada con el pasado sino con el presente. Preguntar por el mínimo teatral en un archivo personal se convirtió, a lo largo del trabajo curatorial, en un punto de reinvención tanto de la idea de archivo como del propio significado que tenía lo teatral dentro de él.

El tercer caso que nos interesa mencionar aquí es el que apuntó a pensar cómo el archivo y lo teatral construyen una temporalidad alternativa en la obra de Mauro Guzmán. En Guzmania (Imagen 3), el artista construyó un set de filmación donde trabajaría en la producción del cuarto episodio de la saga La Guzmania, proyecto en desarrollo desde 2013 en diversos formatos y salas de exhibición. En la sala dispuso diversos elementos para su uso (disfraces, pelucas, escenografías), un escenario y luces, y una pantalla donde se proyectaban los primeros avances de la serie y donde se planeaba proyectar el material que se fuera grabando durante los tres meses de la muestra. La obra planteaba, en este sentido, un tiempo del teatro vinculado con la efimeridad y espontaneidad de las 
improvisaciones y la acción, a la par que un tiempo del archivo en construcción. Lo que se presenta como registro no respondía así a una serie de elementos históricos reordenados o revisitados, sino que el archivo era una consecuencia inmediata de la acción presente. Una acción que se sustenta en una teatralidad drag, en el imaginario de los medios masivos, pero también en la estética del cine experimental y sobre todo en una poética queer que tiene a Guzmán como factótum y personaje principal.

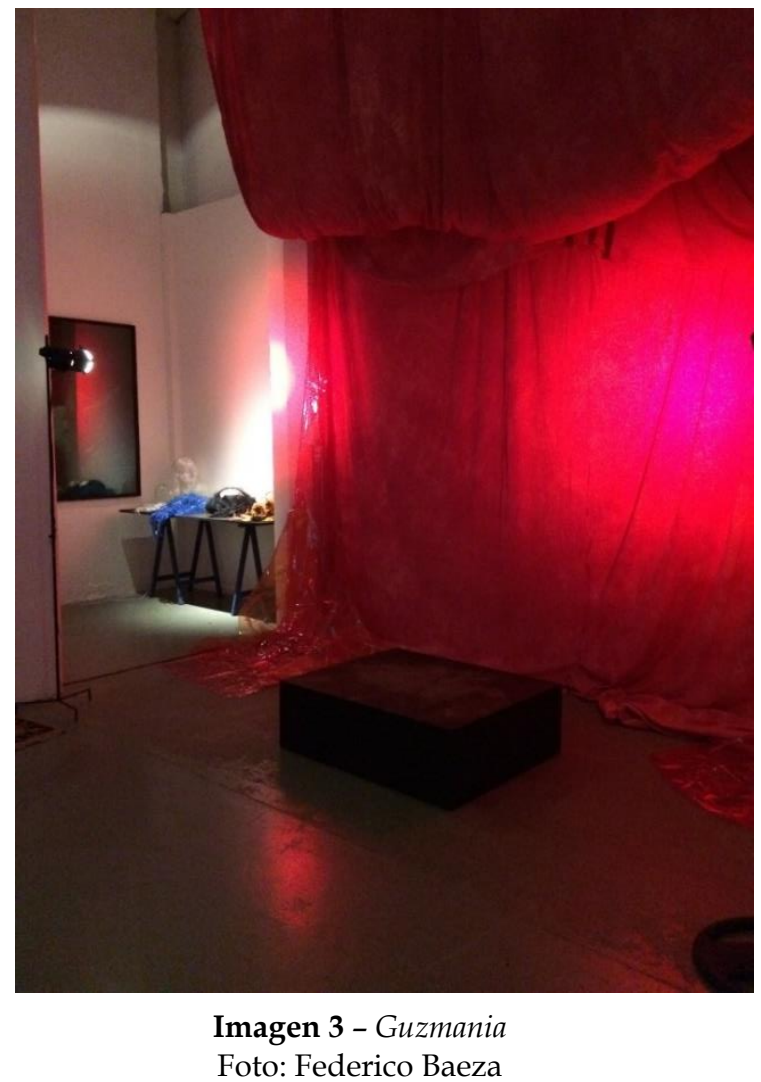

La instalación contaba también con fotografías y objetos del propio artista que contribuían a extrañar la clasificación de lo que podía verse en la sala. Set de filmación como espacio de uso, marco 
de una acción que se constituirá como obra una vez que se transforme en imagen $\mathrm{y}$, a la vez, espacio de exhibición de artefactos artísticos ya producidos. El hacer artístico se configuraba en esa doble temporalidad de la obra acabada y la obra por venir. Entre ambas, una especie de espacio-umbral, el de la instalación, espacio de la performance y de pasaje de formatos.

Finalmente, la exhibición contó con una única obra teatral programada en vivo: El fin del arte de Rafael Spregelburd (Imagen 4) y curaduría invitada de Federico Baeza, que contó con dos funciones y una posterior charla pública entre Spregelburd y Sandra Contreras. El espectáculo, que conforma una trilogía que pudo verse entre 2016 y 2017 en La Plata y Buenos Aires, se estrenó en ArteBA en 2014 con el formato que se presentó en el MACRO: una pieza teatral breve que se espeja con una charla igualmente breve y termina por articular un debate doble, entre la realidad y la ficción, acerca de la definición del arte contemporáneo. Del lado de la ficción, unos profesores de historia del arte son puestos entre la espada y la pared por una señora de Borja, Zaragoza, acusada de destrozar una imagen de Cristo y protagonista de la noticia que termina por viralizarse en la red (por otro lado, hecho real que detona la pieza) y una estudiante con el nombre de la capital francesa, aplazada sin justificación por una tesis sobre lo que considera un verdadero gesto contemporáneo de la señora española. Del lado de la realidad, los profesores, críticos y artistas que se prestan al debate después de la representación. Desde las pinturas rupestres, pasando por los iconoclastas y Warhol, hasta Cecilia Giménez, la artista amateur en cuestión, la pregunta por el arte contemporáneo es una excusa para hablar no tanto del arte, como de la labor del arte: activar el relato de una multiplicidad de prácticas y experiencias (crítica, historia, educación) y poner en movimiento un pensamiento sobre el tiempo presente (lo contemporáneo) que se dibuja en zig-zag (hacia adelante y atrás en la historia, fuera y dentro del canon, más allá y más acá del arte). Heterocronías y heterotopías mediante (Foucault, 1984), la acción de la obra teatral en el museo habilitaba igualmente un pensamiento acerca de las especificidades disciplinares. Así, la pregunta por lo contemporáneo no interceptaba solamente la flecha del tiempo, señalaba igualmente los lugares y las gramáticas 
(fronteras y convenciones) de las artes y de aquellas otras prácticas estéticas de más difícil definición.

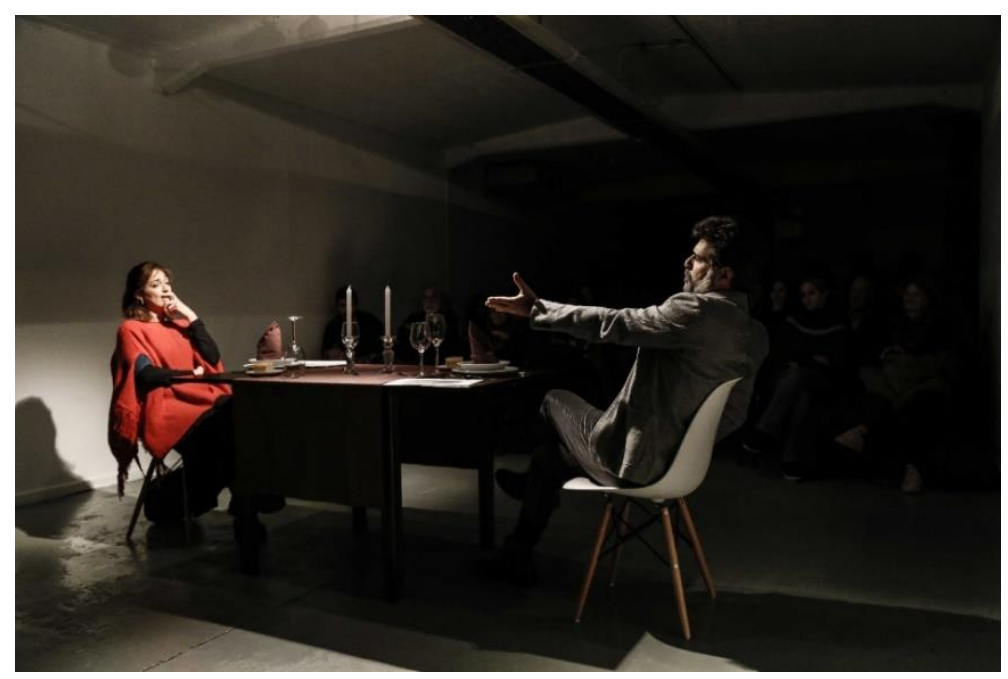

Imagen 4 - El fin del arte

Foto: Guillermo Turin Bootello

\section{Curaduría, autoría y puesta en escena}

Al inicio del trabajo nos preguntábamos de qué modo la investigación e hipótesis que guiaron la exhibición habían alcanzado, afectado a la propia curaduría. El corpus aquí estudiado -él mismo un recorte del conjunto de obras expuestas- nos permitió avanzar no sólo sobre la selección y montaje de obras, instalaciones, registros y archivos de muy distintas características con que contó la muestra, sino también comenzar a vislumbrar la interpelación que la propia producción artística tenía en el trabajo y la reflexión curatorial.

Como puede observarse del análisis del corpus, éste no se exhibía tanto como unidades de sentido discretas, una obra de arte, sino como un prisma que habilitaba un pensamiento sobre tiempos heterogéneos, narraciones parcialmente recuperadas, interrogaciones al canon de lo contemporáneo, señalamientos sobre las representaciones de la corporalidad y la subjetividad. También ponía en escena un pensamiento y un hacer fuertemente marcado por un 
horizonte posautónomo y posproductivo (Bourriaud, 2007); productos que se muestran reciclados, apropiados, que operan con las noticias que circulan en internet, sobre la iconografía, los gestos y relatos masivos, sobre unos registros y documentos que se asoman a experiencias y afectividades de comunidades a la vez precarias y altamente significativas $\mathrm{y}$, sobre todo, al carácter colectivo de la educación, la producción y la historia del arte. Aquí la referencia al teatro se vuelve inevitable, casi un lugar común, él mismo una práctica grupal por excelencia.

La cuestión autoral se constituye, desde el punto de vista del corpus analizado y desde el prisma teatral que lo reunió y lo hizo legible, como un efecto de múltiples miradas, voces, cuerpos y escrituras. La propia curaduría del proyecto se configuró como un trabajo a cuatro voces. Así, Mínimo teatral se recorta claramente en el paisaje caracterizado por Boris Groys: “en las últimas décadas asistimos a la emergencia de proyectos curatoriales innovadores que parecen darle mayor poder al curador para actuar de una manera soberana y autoral. Y hemos visto la emergencia de prácticas estéticas que buscan plantearse como en colaboración, descentralizadas, sin autoría, democráticas" (2014, p. 57).

Creemos que lo singular de la exhibición, en tanto investigación e interrogación por aquello que puede habilitar el teatro como pensamiento no es tanto el hecho de que el museo no pueda arrojar él mismo sus propias ideas e hipótesis sobre las prácticas artísticas y curatoriales contemporáneas, sino que el prisma teatral las potencia de un modo particular. Respecto del problema de la autoría - y más ampliamente del problema de la "escritura" y la "lectura" - creemos que el teatro ayuda a hacer visible aquello que Giorgio Agamben (2009) señalaba en relación a los modos de producción de la subjetividad: no tanto en los términos de una realidad sustancial presente, sino en tanto gesto que se muestra y resiste justamente en el punto en que los dispositivos la capturan y la ponen en juego. En este sentido, nuestro corpus - constituido por cuerpos, acciones y voces atravesados por múltiples formatos, saberes, disciplinas y dispositivos - configura un conjunto heterogéneo de subjetividades puestas (a jugar) en el museo, sin quedar asimiladas por completo a él. Asimismo, analizábamos la relación escritura/lectura en los términos de un paisaje fuertemente marcado por los usos diversos 
del archivo cultural y la autoría colectiva. Siguiendo a Diana Klinger (2013), nos interesa señalar igualmente el modo en que el prisma teatral nos permite explorar las posibilidades del arte de afectar al otro, de ofrecerse como forma vinculante y transitiva, figurada en el difícil equilibrio entre la identificación y la irreductibilidad.

Entre 2007 y 2008 se llevó a cabo en las ciudades de Barcelona y Lisboa una importante exhibición sobre las relaciones entre artes visuales y teatro que se llamó Un teatro sin teatro. ${ }^{9}$ En su catálogo, Patricia Falguières reflexionaba:

¿Y estamos seguros de haber aprendido la naturaleza de las relaciones que las artes plásticas trabaron con el teatro a lo largo del siglo XX y los envites que entrañaban? Uno de los malentendidos más corrientes al respecto es el de imaginar que el auge de la performance y el happening (en lo que se resumiría un siglo de relaciones artes/teatro) tomó de la cultura teatral esa exhortación al aquí y ahora que parece especificar su género. Como si la referencia al teatro significara para el arte un requerimiento de "vida". ¿Qué es lo que convirtió el escenario teatral en una zona de experimentación para las artes del siglo $X X$ ? Una relación singular de los signos con la superficie que llamamos "escenario". [...] ese espacio que no es nada sustancial y que, como contrapartida, instaura, con su delimitación, el juego de los signos que es la representación (MACBA, 2007, p. 30-31).

No sería entonces el tiempo presente o la presencia en vivo el efecto (de sentido) que el montaje y el archivo teatral instalaría (como reflexión) en el museo. Lo que el teatro habilita, en tanto pensamiento, es la visibilización, la ostentación de los dispositivos de la exhibición como puesta en escena, representación, narración del arte y su historia, pero también de los espectadores y de la comunidad. El teatro potencia, en este sentido, un pensamiento sobre las dinámicas entre subjetividades y dispositivos, comunicación e impenetrabilidad. El teatro habilita el juego y la curaduría acomete la ambiciosa tarea de interpelar al otro. Se abre el museo; y los archivos, acciones, voces e imágenes son llevados a escena.

${ }^{9}$ Curaduría de Bernard Blistène y Yann Chateigné, con la colaboración de Pedro Romero y Bartolomeu Marí. Cf. MACBA (2007). 


\section{Referências}

AGAMBEN, Giorgio (2002). Lo que queda de Auschwitz: el archivo y el testigo. Homo sacer III. Valencia: Pre-Textos.

AGAMBEN, Giorgio (2009). El autor como gesto. In: AGAMBEN, Giorgio Profanaciones. Buenos Aires: Adriana Hidalgo.

BOURRIAUD, Nicolas (2007). Postproducción. La cultura como escenario: modos en que la cultura reprograma el mundo contemporáneo. Buenos Aires: Adriana Hidalgo.

DERRIDA, Jacques (1997). Mal de archivo: una impresión freudiana. Madrid: Trotta.

FARGE, Arlette (1991). La atracción del archivo. Valencia: Alfons El Magnanim.

FOUCAULT, Michel (1967/1984). Des espaces autres. Architecture, Mouvement, Continuité, Paris, n. 5, p. 46-49, out.

FOUCAULT, Michel (1969/1996). La arqueología del saber. México: Siglo XXI.

GARBATZKY, Irina (2017). Mínimo teatral. La invención del acto. Guía de Visita, Rosario, Castagnino+Macro, n. 31.

GROYS, Boris (2011). El curador como iconoclasta. Denken Pensée Thought Mysl..., La Habana, n. 2, p. 23-34, 15 feb.

GROYS, Boris (2014). Volverse público: las transformaciones del arte en el ágora contemporánea. Buenos Aires: Caja Negra.

KLINGER, Diana (2013). Sobre a (im)possibildade de alcançar o outro. Grumo, Buenos Aires/Rio de Janeiro, n. 10, p. 84-89. Disponible en: <https://goo.gl/Lq4fgR>. Acceso: 23 mar. 2018.

MACBA - MUSEU D'ART CONTEMPORANI DE BARCELONA (Org.). (2007). Un teatro sin teatro. Barcelona: Museu d'Art Contemporani de Barcelona; Lisboa: Fundaçao de Arte Moderna e Contemporanea/Colecçao Berardo. Catálogo de exposición

PINTA, María Fernanda (2017). Mínimo teatral. Cantidad necesaria. Guía de Visita, Rosario, Castagnino+Macro, n. 31.

Recebido em 2 de abril de 2018.

Aprovado em 26 de junho de 2018. 


\title{
resumo/abstract/resumen
}

\section{Ante o teatro, no museu, desde o arquivo. Modos cênicos (e autorais) da arte contemporânea}

\author{
María Fernanda Pinta
}

Irina Garbatzky

Na exposição Mínimo teatral (Museo Macro, Rosario, 2017) trabalhamos, como curadores, nas ressonâncias do teatro na arte contemporânea, explorando diferentes formas de apropriação da teatralidade e da encenação. Pretendíamos incentivar um diálogo entre as artes visuais e artísticas, mesmo quando as trocas não ocorriam em termos de referência e/ou comentários de um em relação ao outro. Ao mesmo tempo, não pretendíamos formular uma história da arte (história do campo visual e teatral, história de suas conversas, história de seus desacordos), ainda que fizéssemos uma pergunta sobre os usos do arquivo e seus efeitos sobre uma possível conceituação de tempo. O presente trabalho busca traçar uma história e uma reflexão sobre essa experiência. As perguntas são: Quais áreas (sensíveis, sociais, produtivas) abre o pensamento do teatro? Quais são os efeitos da montagem e do arquivo teatral no museu? Quais seriam os efeitos sobre a conceituação e usos do tempo? E, finalmente, quais implicações na curadoria levaram à investigação e às hipóteses arriscadas para a amostra, tanto no que diz respeito ao diálogo teatro/arte quanto ao ponto de vista adotado em relação ao arquivo.

Palavras-chave: artista, curador, teatro, arquivo, arte contemporânea latinoamericana.

\section{In front of the theatre, at the museum, from the archive. Scenic (and authorial) modes of contemporary art}

María Fernanda Pinta

Irina Garbatzky

In the Minimo teatral exhibition (Macro Museum, Rosario, 2017) we worked, as curators, on how theatre resonates in contemporary art, exploring the different appropriations of theatricality and staging in various art forms. Our intention was to promote a dialogue between visual and scenic arts, even when the exchanges did not occur through direct reference and/or comments between different artistic expressions. At the same time, we were not trying to formulate a history of art (history of the disciplinary field, of their conversations or misunderstandings), though we did inquire into the uses of the archive and its effects in a possible conceptualization of time. 
This essay proposes to present a perspective and a reflection about that experience. The questions broached are: Which zones (sensitive, social, productive) are enabled by theatrical thought? Which are the effects of the assembly and archive of theatre in the museum? Which would be the effects on the conceptualization and the uses of time? And finally, what repercussions did the research and the hypothesis proposed by the exhibit have for the curatorship not only in what it pertains to the dialogue between theater and art, but also in regards to the archive.

Keywords: artists, curators, theater, archives, Latin-American contemporary art.

\section{Ante el teatro, en el museo, desde el archivo: modos escénicos (y autorales) del arte contemporáneo}

María Fernanda Pinta

Irina Garbatzky

En la exhibición Mínimo teatral (Museo Macro, Rosario, 2017) trabajamos, en tanto curadoras, sobre las resonancias del teatro en el arte contemporáneo, explorando distintos modos de apropiación de la teatralidad y la puesta en escena. Teníamos la intención de propiciar un diálogo entre artes visuales y escénicas, aún cuando los intercambios no se produjeran en términos de referencia y/o comentarios de uno con respecto al otro. Al mismo tiempo, no pretendíamos formular una historia del arte (historia del campo visual y teatral, historia de sus conversaciones, historia de sus desencuentros), aunque hiciéramos una pregunta por los usos del archivo y sus efectos en una posible conceptualización del tiempo. El presente trabajo busca tramar un relato y una reflexión sobre aquella experiencia. Las preguntas son: ¿Qué zonas (sensibles, sociales, productivas) abre el pensamiento del teatro? ¿Cuáles son los efectos del montaje y del archivo teatral en el museo? ¿Cuáles serían los efectos sobre la conceptualización y los usos del tiempo? Y finalmente, qué implicancias sobre la curaduría arrojó la investigación y las hipótesis arriesgadas para la muestra, tanto en lo concerniente al diálogo teatro/artes como al punto de vista adoptado respecto del archivo.

Palabras clave: artista, curador, teatro, archivo, arte latinoamericano contemporáneo. 